\title{
PSYCHOSOMATIC PROBLEMS IN CAREGIVERS OF PATIENTS WITH MAJOR MENTAL ILLNESSES
}

\author{
KS Sumi $^{1^{*}}$, Varghese P Punnoose ${ }^{2}$, Nisha Cyriac ${ }^{3}$ \\ ${ }^{1}$ Junior Resident, ${ }^{2}$ Professor and Head, ${ }^{3}$ Assistant Professor \\ Dept. of Psychiatry, Govt. Medical College, Kottayam. \\ Correspondence: Dept. of Psychiatry, Govt. Medical College, Kottayam. Email: drsumiaswin@gmail.com
}

\begin{abstract}
Aim: To assess the psychosomatic problems among caregivers of patients with major mental illnesses. Materials and Methods: In this descriptive study, based on purposive sampling technique, 120 caregivers of patients with major mental illness admitted under Department of Psychiatry in a tertiary care centre were selected. Standardized four-dimensional symptom questionnaires were used to assess psychosomatic problems in caregivers of patients with major mental illnesses.

Results: Caregivers of the patients with major mental illness had moderately high to high level of psychosomatic problems. There was no significant difference in psychosomatic problems of caregivers among major mental illnesses (Schizophrenia, mood disorders, and alcohol dependence syndrome).

Conclusion: Caregivers of patients with major mental illnesses experience psychosomatic problems. There is no significant difference between the specific diagnosis of the patient and psychosomatic problems of caregivers.
\end{abstract}

Keywords: Psychosomatic problems, caregivers, major mental illnesses.

\section{BACKGROUND AND RATIONALE}

World Health Organization (WHO), in 2013, stated that globally, in both developed and developing countries, 1 in 4 (25\%) suffer from mental disorders. Four of the six leading causes of Years Lived with Disability are depression, alcohol use disorders, schizophrenia, and bipolar disorder. ${ }^{1}$

Epidemiological studies report prevalence rates for psychiatric disorders varying from 9.5 to $370 / 1000$ population in India. About $20 \%$ of the adult population in the community is affected by one or the other psychiatric disorder. More than $70 \%$ of mentally challenged patients live with their families, and family is the major care provider. ${ }^{1}$ In India, an estimated $30 \%$ of the population suffers from some form of psychiatric disorder. Twenty million Indian families have at least one member suffering from schizophrenia. More than $12 \%$ of Indian children aged 1-16 years suffer from mental disorders and the incidence of mental retardation is also high. Severe mental disorders that include schizophrenia, bipolar disorders and major depression affect nearly $2 \%$ of our population. ${ }^{2}$

The occurrence of mental illness in a loved one is a catastrophic event and often results in enduring consequences for the family. Thus, the impact of the illness is experienced not only by the affected member but by the entire family as well. Families have to shoulder a heavy burden in means of money also. This poses an enormous challenge to the families since it demands considerable time and effort from them in addition to other attributes such as patience, endurance, innovativeness, and 
resourcefulness. It is not surprising, therefore, that those families often feel overwhelmed and helpless in addressing this situation. ${ }^{3}$

As the illness progresses, usually one person in the family comes forward as the caregiver. Much of the caregiving responsibility will fall on him/ her. ${ }^{4}$ This causes an alteration in physiological functioning of the individual due to psychological factors. "Psychosomatic disorders" indicate changes which occur both in psychic-mind and somatic-body. People can convert transference of unexpressed emotions into physical symptoms, and the phenomenon is called 'somatisation'. As people are largely ignorant of the underlying psychological factors, they usually obtain medical treatment for the physical symptoms and do not opt for a psychiatric evaluation. Chronic stress seems to play a particularly important part and can influence not only the causes of the illness but can also worsen the symptoms and affect the course of the disorder. ${ }^{5}$

Chronic diseases place a considerable burden on family caregivers who take the sole responsibility of caring for chronically ill patients. The profound psychosocial, physical, and financial impact on the family of individuals with severe mental illness is comparable to that of persons with other illnesses such as Alzheimer's disease or cancer. ${ }^{6}$

Living with and caring for an individual with a psychiatric disorder seems inherently stressful. Caregivers experience significantly higher level of psychological distress than the general population. Studies have shown that taking care of a mentally ill person will cause the caregiver to face feelings of insecurity, sorrow, and worry. ${ }^{7}$

Mental health professionals have an important duty to acknowledge the burden of caregivers. They are in a position to render support and refer them to get support through social workers and community agencies. Such measures would ensure caregiver wellbeing. For that, mental health professionals have to assess the psychosomatic problems and provide them adequate care to get out from that scenario. Many studies have been done to assess the burden of caregivers of mentally ill. Caregiver burden is a broad aspect which includes physical, mental, emotional, social, and financial aspects.

\section{OBJECTIVES}

1. To assess psychosomatic problems among caregivers of patients with major mental illnesses.

2. To compare the psychosomatic problems of caregivers of patients with schizophrenia, mood disorders, and alcohol dependence syndrome.

\section{OPERATIONAL DEFINITIONS}

Psychosomatic problems: In this study, "psychosomatic problems" are the complaints and symptoms reported by the caregivers, like somatization, distress, depression, and anxiety, and are assessed using standardized Four-Dimensional Symptom Questionnaire (4DSQ).

Caregiver: In this study, "caregiver" is a person who resides with the patient and holds major responsibility in the care of the patient for a minimum period of two years and is bonded by a relation - mother/father, husband/wife, brother/sister, son/daughter, son-in-law/ daughter-in-law.

Major mental illnesses: In this study, major mental illnesses included are schizophrenia, mood disorders and alcohol dependence syndrome as diagnosed by International Classification of Diseases $10^{\text {th }}$ revision (ICD- 10 ) criteria $^{8}$ and having a duration of two or more years.

\section{METHODOLOGY}

This was a descriptive study conducted in the Department of Psychiatry in a tertiary care centre. The study duration was one year from $1^{\text {st }}$ July 2015 to $30^{\text {th }}$ June 2016. The study population comprised of caregivers of patients with a major mental illness who satisfied the inclusion criteria.

\section{Inclusion Criteria}

1. Caregivers who are willing to participate in the study.

2. Caregivers who are able to comprehend the instructions in Malayalam. 


\section{Exclusion Criteria}

1. Caregivers who are already diagnosed to have psychiatric disorders as per ICD-10 criteria and are on treatment.

2. Caregivers who are below 18 years of age.

The study sample constituted 120 caregivers. One caregiver per patient and the non- probability purposive sampling method were used.

\section{STUDY TOOLS}

\section{Sociodemographic datasheet}

An interview schedule was used to assess the demographic data of caregivers such as age, gender, marital status, relationship with the patient, education, domicile, occupation, and total duration of caregiving.

\section{Four-Dimensional Symptom Questionnaire}

The Four-Dimensional Symptom Questionnaire (4DSQ), developed by Terluin (1996) ${ }^{9}$, is a selfreported questionnaire comprising 50 items distributed over four scales. It is developed for general practice to assess the level of distress, somatization, depression, and anxiety among the study participants. One important feature of this tool is that items are worded as questions similar to those that can be asked in everyday primary care practice. The reference period is the last week.

The 'somatisation' scale measures a range of common physical symptoms. The 'distress' scale measures nonspecific symptoms of psychopathology, ranging from worrying and irritability to fatigue and demoralization. The 'depression' scale measures severe anhedonia and depressive thoughts, including suicidal ideation, symptoms that are characteristic of depressive disorders. The 'anxiety' dimension encompasses symptoms such as free-floating anxiety, panic attacks, phobic anxiety, and avoidance behaviour. Reliability of the 4DSQ scales is high, with alphacoefficients ranging from 0.84 to 0.94 and test-retest coefficients ranging from 0.89 to 0.94 .

\section{STUDY PROCEDURE}

Caregivers who met the inclusion criteria were selected using non-probability purposive sampling technique. Rapport was established with the caregivers, the purpose of the study was explained to them, and informed consent was obtained. Basic information of caregiver and patient was collected using sociodemographic data sheet. Psychosomatic problems of caregivers were assessed by 4DSQ. Sociodemographic data were analysed by using frequency and percent. Chi-square test was used to compare the psychosomatic problems of caregivers of patients with schizophrenia, mood disorders, and alcohol dependence syndrome. The analysis was done using SPSS version 22.

\section{RESULTS}

\section{Sample characteristics:}

$28.3 \%$ of caregivers were aged $>58$ years. The majority $(59.2 \%)$ were females, and $78.3 \%$ were married (Table 1). Majority of caregivers were either parents $(34.2 \%)$ or spouses (35\%). Most were

Table 1: Frequency distribution and percentage of caregivers of patients with major mental illnesses based on age, gender, and marital status $(N=120)$

\begin{tabular}{|l|c|c|}
\hline VARIABLES & $\mathbf{n}$ & $\mathbf{\%}$ \\
\hline Age in years & & \\
\hline $18-27$ & 16 & 13.3 \\
\hline $28-37$ & 20 & 16.7 \\
\hline $38-47$ & 21 & 17.5 \\
\hline $48-57$ & 29 & 24.2 \\
\hline$>58$ & 34 & 28.3 \\
\hline Gender & & \\
\hline Male & 49 & 40.8 \\
\hline Female & 71 & 59.2 \\
\hline Marital status & & \\
\hline Unmarried & 17 & 14.2 \\
\hline Married & 94 & 78.3 \\
\hline Separated & 1 & 0.8 \\
\hline Widow/ Widower & 8 & 6.7 \\
\hline
\end{tabular}


educated up to primary or secondary level. The majority $(76.7 \%)$ belonged to rural domicile (Table 2).

$41.7 \%$ of caregivers were unemployed. The majority $(40 \%)$ were caregiving only for $2-6$ years (Table 3).

Psychosomatic problems of caregivers of patients with major mental illnesses:

Somatisation level was moderately high in $47.5 \%$, $40 \%$ and $30 \%$ of caregivers of patients with schizophrenia, mood disorder, and alcohol dependence respectively. Distress level was found to be high in $30 \%$ each among caregivers of patients with schizophrenia and mood disorder while $42.5 \%$ of caregivers of patients with alcohol dependence were highly distressed (Table 4).

Table 2: Frequency distribution and percentage of caregivers of patients with major mental illnesses based on relationship with the patient, educational level and domicile $(N=120)$

\begin{tabular}{|l|c|c|}
\hline VARIABLES & n & \% \\
\hline Relationship with patient & \multicolumn{2}{|l|}{} \\
\hline Parents & 41 & 34.2 \\
\hline Spouse & 42 & 35.0 \\
\hline Son/ daughter & 10 & 8.3 \\
\hline Brother/ sister & 21 & 17.5 \\
\hline Son in law/daughter in law & 6 & 5.0 \\
\hline Educational level & & \\
\hline Primary & 42 & 35.0 \\
\hline Secondary & 43 & 35.8 \\
\hline Pre-university & 21 & 17.5 \\
\hline University & 10 & 8.3 \\
\hline Other & 4 & 3.3 \\
\hline Domicile & & \\
\hline Urban & 28 & 23.3 \\
\hline Rural & 92 & 76.7 \\
\hline
\end{tabular}

Table 3: Frequency distribution and percentage of caregivers of patients with major mental illnesses based on occupation and total years of caregiving after the diagnosis $(N=120)$

\begin{tabular}{|l|c|c|}
\hline VARIABLES & $\mathbf{n}$ & $\mathbf{\%}$ \\
\hline Occupation & \multicolumn{2}{|c|}{} \\
\hline Not working & 50 & 41.7 \\
\hline Government Job & 10 & 8.3 \\
Private sector & 14 & 11.7 \\
\hline Self-employed & 20 & 16.7 \\
\hline Daily wages & 25 & 20.8 \\
\hline Contract basis & 1 & 0.8 \\
\hline Total years of caregiving after the diagnosis & \\
\hline 2-6 years & 48 & 40.0 \\
\hline 7-11 years & 23 & 19.2 \\
12-16 years & 18 & 15.0 \\
\hline 17-21years & 12 & 10.0 \\
\hline >21 years & 19 & 15.8 \\
\hline
\end{tabular}

Level of depression was high in $47.5 \%, 30 \%$ and $40 \%$ of caregivers of patients with schizophrenia, mood disorder, and alcohol dependence respectively. Moderately high level of anxiety was found in $22.5 \%, 12.5 \%$ and $27.5 \%$ of caregivers of patients with schizophrenia, mood disorder and alcohol dependence respectively (Table 4).

Analysis revealed no significant difference in psychosomatic problems (somatisation, distress, depression, and anxiety) of caregivers of patients with schizophrenia, mood disorders or alcohol dependence syndrome (Table 4).

\section{DISCUSSION}

The present study focused on the psychosomatic problems among caregivers of patients with major mental illnesses attending a tertiary care centre.

It was found that $28.3 \%$ of the caregivers had age more than 58 years. The majority $(59.2 \%)$ of the caregivers were females. Caregivers are more likely to be women in many parts of the world. A study conducted in the United Kingdom found that about 
Table 4: Comparison of psychosomatic problems among caregivers of patients with schizophrenia, mood disorders and alcohol dependence syndrome $(n=120)$

\begin{tabular}{|c|c|c|c|c|c|c|c|c|}
\hline \multirow{3}{*}{$\begin{array}{l}\text { Psychosomatic problems of } \\
\text { caregivers }\end{array}$} & \multicolumn{6}{|c|}{ Diagnosis of the patient } & & \\
\hline & \multicolumn{2}{|c|}{$\begin{array}{l}\text { Schizophrenia } \\
\quad(n=40)\end{array}$} & \multicolumn{2}{|c|}{$\begin{array}{l}\text { Mood } \\
\text { disorder } \\
(n=40)\end{array}$} & \multicolumn{2}{|c|}{$\begin{array}{l}\text { Alcohol } \\
\text { dependence } \\
\text { syndrome } \\
(n=40)\end{array}$} & \multirow[t]{2}{*}{ Chi- square } & \multirow[t]{2}{*}{$P$ value } \\
\hline & $\mathrm{f}$ & $\%$ & $\mathrm{f}$ & $\%$ & $\mathrm{f}$ & $\%$ & & \\
\hline \multicolumn{9}{|l|}{ Somatisation level } \\
\hline Low $(0-10)$ & 17 & 42.5 & 23 & 57.5 & 21 & 52.5 & \multirow[t]{3}{*}{6.993} & \multirow[t]{3}{*}{0.136} \\
\hline Moderately high (11-20) & 19 & 47.5 & 16 & 40.0 & 12 & 30.0 & & \\
\hline High $(21-32)$ & 4 & 10.0 & 1 & 2.5 & 7 & 17.5 & & \\
\hline \multicolumn{9}{|l|}{ Distress level } \\
\hline Low $(0-10)$ & 6 & 15.0 & 14 & 35.0 & 7 & 17.5 & \multirow[t]{3}{*}{7.442} & \multirow[t]{3}{*}{0.114} \\
\hline Moderately high (11-20) & 22 & 55.0 & 14 & 35.0 & 16 & 40 & & \\
\hline High $(21-32)$ & 12 & 30.0 & 12 & 30.0 & 17 & 42.5 & & \\
\hline \multicolumn{9}{|l|}{ Depression level } \\
\hline Low $(0-2)$ & 15 & 37.5 & 19 & 47.5 & 15 & 37.5 & \multirow[t]{3}{*}{2.978} & \multirow[t]{3}{*}{0.562} \\
\hline Moderately high (3-5) & 6 & 15.0 & 9 & 22.5 & 9 & 22.5 & & \\
\hline High (6-12) & 19 & 47.5 & 12 & 30 & 16 & 40 & & \\
\hline \multicolumn{9}{|l|}{ Anxiety level } \\
\hline Low $(0-7)$ & 27 & 67.5 & 32 & 80.0 & 27 & 67.5 & \multirow[t]{3}{*}{3.488} & \multirow[t]{3}{*}{0.480} \\
\hline Moderately high (8-12) & 9 & 22.5 & 5 & 12.5 & 11 & 27.5 & & \\
\hline High $(13-24)$ & 4 & 10.0 & 3 & 7.5 & 2 & 5.0 & & \\
\hline
\end{tabular}

$58 \%$ of the caregivers were women and Asian studies found that about $70 \%$ of family caregivers were females. ${ }^{8}$ The World Federation of Mental Health estimated that, globally, about $80 \%$ of the caregivers were women. ${ }^{9}$ This study too has similar findings may be because in most families in Kerala males are the breadwinners and females look after the home and care for the patients. In the present study, the majority $(78.3 \%)$ of the caregivers were married, $35 \%$ of caregivers were spouses, and 34.2\% were parents. A study conducted in Bangalore to assess burden among caregivers of the mentally ill patients also found that $23.3 \%$ of the caregivers belonged to the spouse category. ${ }^{10}$

In the present study, the majority of caregivers of patients with major mental illnesses (35.0\%) had secondary school education. We also found that majority (41.7\%) of caregivers of patients with major mental illnesses was not working. A study conducted in Canada found that approximately 30\% of informal caregivers work outside the home. Over one million working Canadians take care of a person diagnosed with a mental illness. Of these, one-third report that it interferes with their paid job due to chronic health problems, depression, and excess stress when the caregiving increases in intensity. ${ }^{11}$ Caregivers could not get enough time to go for a job while caring for a patient with a major mental illness.

A study conducted by National Alliance for Caregiving found that about one in ten caregivers report that caregiving has caused their physical health to get worse. ${ }^{12}$ Caregivers also reported chronic conditions (including heart attack/heart 
disease, cancer, diabetes, and arthritis) at nearly twice the rate of non-caregivers. Caregivers suffer from increased rates of physical ailments (including acid reflux, headaches, and pain/aching), increased tendency to develop serious illness, and have high levels of obesity and bodily pain. ${ }^{13}$ A study conducted in Malaysia found psychological distress in $14 \%$ of the caregivers and depressive disorders in $6 \%$ of the caregivers. ${ }^{14}$ Studies had consistently shown that at least one-third of caring relatives had elevated levels of anxiety or depression connected with the caring role. ${ }^{15} \mathrm{~A}$ research study conducted at Sri Lanka to assess the impact of long-term psychotic disorders on caregivers found that up to $60 \%$ of caregivers feel very anxious and depressed. ${ }^{16}$

One of the major findings of the present study was that there was no significant difference in psychosomatic problems of caregivers of patients with schizophrenia, mood disorders or alcohol dependence syndrome. This finding was contradictory to the findings of some past studies that caregivers of schizophrenia had a higher level of distress, depression, and anxiety than caregivers of patients with other major mental illnesses. A cross-sectional study conducted in India to compare family care burden in families of schizophrenia patients and patients having depressive disorders found that caregivers of patients with schizophrenia had significantly increased mean burden score. ${ }^{17} \mathrm{~A}$ study conducted in Hyderabad to assess the extent and pattern of burden felt by the caregivers of patients with schizophrenia in comparison with bipolar disorder found that the caregivers of schizophrenia had significantly higher total burden score. ${ }^{18}$ Such a contradictory finding in this study may be because the study included caregivers of only inpatients who were in an active phase of the illness, which might have coloured the responses given by the caregivers.

\section{LIMITATIONS}

Generalisability of our findings is limited due to only one setting and limited sample size (120). Considering the time factor and feasibility, our sample included caregivers of only inpatients who were mostly in an active phase of illness, and this might have confounded the results.

\section{CONCLUSIONS}

The present study revealed that caregivers of patients with major mental illnesses experience psychosomatic problems. This study also found that there were no significant differences between the psychosomatic problems experienced by the caregivers of the three groups of patients. Findings of the study suggested that caregivers of patients with major mental illnesses experience different psychosomatic problems, which need immediate attention.

\section{RECOMMENDATIONS}

On the basis of the present study, following recommendations are made for the future:

- A similar study can be conducted using large sample size with probability sampling technique.

- A study can be done to compare the psychosomatic problems of caregivers of patients with major mental illnesses and caregivers of patients with chronic medical illnesses.

- A comparative study can be conducted to assess the psychosomatic problems of caregivers attending government and private hospitals.

- Day care centres and occupational training centres can be started for mentally ill patients in attachment to primary health centres.

\section{REFERENCES}

1. Mental health 2013: An Important Public Health Issue; NAMI of Greater Chicago2013July; Available from: http://www.namigc.org/wpcontent

/uploads/2013/01/Mental Illness Fact Sheet-July 2013.pdf

2. Math SB, Srinivasaraju R. Indian psychiatric epidemiological studies: Learning from the past. Indian J Psychiatry 2010; 52(7):95-103.

3. Srinivasan N. We are not alone: Family care of persons with mental illness Malleshwaram, Bangalore: Association for Mentally Disabled, (AMEND) Bangalore and Action for Mental Illness (ACMI) Bangalore; 2003. 
4. Zvěřová M. Frequency of some psychosomatic symptoms in informal caregivers Prague's experience. Activitas Nervosa Superior Rediviva 2012; 54(2): 71-132.

5. Videbeck S. Psychiatric-mental health nursing. 1st ed. Philadelphia: Wolters Kluwer Health/Lippincott Williams \& Wilkins; 2011.

6. Swaroop N, Shilpa R, Goud BR, Maria A, Tony MP, Pal A, et al. Burden among caregivers of mentally- ill patients: A rural community - based study. Int J Res Dev Health 2013; 1(2):29-34.

7. Robert PJ, Marin FM. The Stress of Caregivers. Mammoth Magazine. 10 March 2011; 1-2.

8. World Health Organization. The ICD-10 classification of mental and behavioural disorders: clinical descriptions and diagnostic guidelines. Geneva: World Health Organization; 1992.

9. Terluin B. De vierdimensionale klachtenlijst (4DKL). Een vragenlijst voor het meten van distress, depressie, angst en somatisatie [The Four-Dimensional Symptom Questionnaire (4DSQ). A questionnaire to measure distress, depression, anxiety, and somatization] Huisarts Wet 1996; 39:538-47.

10. Caregiver Health. https://caregiver.org/caregiverhealth (accessed 30 June 2016).

11. The caregiver perspective caregivers of individuals with bipolar disorder, schizophrenia and schizoaffective disorder. http://wfmh.com/wp content/ uploads/2013/11/WFMH_GIAS_Caregiver_FactShee t.pdf
12. Agrawal G. Burden among caregivers of mentally-ill patients: a rural community-based study. Int J Res Dev Health 2013; 1(2):29-34.

13. Cmha.ca, (2004). Caregiver Support and Mental Health Canadian Mental Health Association. [online] Available at: http://www.cmha.ca/public__ policy/caregiversupport-and-mental-health/\#.U5_-j5SSyRU

14. Evercare. Caregivers in decline: a close-up look at the health risks of caring for a loved one. National Alliance for Caregiving, 2006.

15. Family Caregiver Alliance. Women and Care giving: Facts and Figures. https://caregiver.org/women-andcaregiving-facts-and-figures

16. Osman CB, Alipah B, Tutiiryani MD, Ainsah O. Depressive disorders and family functioning among the caregivers of patients with schizophrenia. East Asian Archives of Psychiatry 2010; 20(3):101-8.

17. Fan CC, Chen YY. Factors associated with care burden and quality of life among caregivers of the mentally ill in Chinese society. Int J Soc Psychiatry 2011; 57(2): 195206.

18. De'silva D, De'Silva S. A preliminary study of the impact of long-term psychotic disorder on patients' families. Ceylon Medical Journal 2001; 46 (4): 121-3.

19. Koujalgi SR, Patil SR. Family burden in patient with schizophrenia and depressive disorder: A comparative study. Indian J Psychol Med 2013; 35: 251-5.

20. Vasudeva S, Sekhar CK, Rao PG. Caregivers burden of patients with schizophrenia and bipolar disorder: A sectional study. Indian J Psychol Med 2013; 35: 352-7

\footnotetext{
Source of support: None

Conflict of interest: None declared
}

First submitted: $5^{\text {th }}$ October 2016

Published online: $8^{\text {th }}$ January 2018 